\title{
Ator, dobrador de tempo
}

\author{
Actor, timebender
}

Mariana Baruco Machado Andraus

Mariana Baruco Machado Andraus

Docente do Departamento de Artes Corporais

da Universidade Estadual de Campinas (Unicamp)

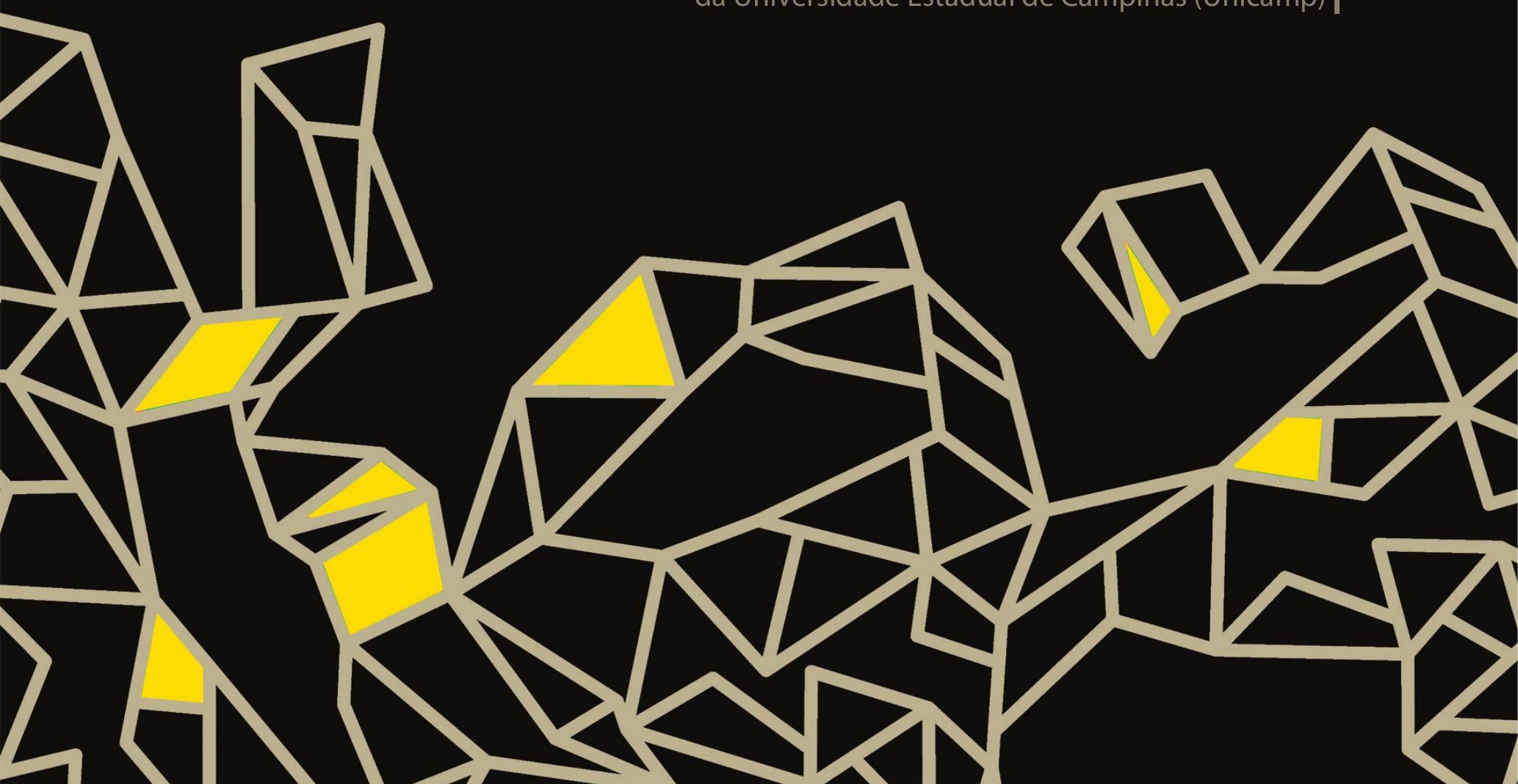




\section{Resumo}

Este artigo elabora uma reflexão sobre o conceito de tempo na arte do ator, estendendo-o ao dançarino e ao performer, em analogia com o conceito de "dobra", presente na série de desenhos animados Avatar: a lenda de Aang. Também analisa a noção de tempo expandido existente nas linguagens da cena, tanto do ponto de vista da elaboração do gesto quanto da construção de roteiro dramatúrgico. Coloca a noção de tempo cênico em diálogo com a noção de subjetivação.

Palavras-chave: Tempo cênico, Arte do ator, Arte do dançarino, Arte do performer, Subjetivação.

\section{Abstract}

This article presents a reflection on the concept of time in the actor's art, extending it also to the dancer and performer, in an analogy with the concept of 'bending' in the animated series Avatar: the last Airbender. It also analyses the notion of expanded time contained in the languages of the scene, both from the point of view of gesture creation as from the construction of dramaturgical script. The notion of scenic time is put in a dialogue with the notion of subjectivity.

Keywords: Scenic time, Actor's art, Art dancer, Performer art, Subjectivity.

Este artigo discorre sobre o conceito de tempo na arte do ator, estendendo-o ao dançarino e ao performer, em analogia com o conceito de "dobra", presente na série de desenhos animados Avatar: a lenda de Aang, analisando especificamente a noção de tempo expandido existente nas linguagens da cena. A reflexão parte de estudo anterior (ANDRAUS, 2014), no qual se examinou a dinâmica da luta como base poética para improvisações a partir da subversão da noção de tempo: enquanto na luta o objetivo dos sujeitos é finalizá-la, no improviso cênico tende-se à manutenção dos conflitos, afetando, deste modo, a própria qualidade do tempo.

O referido trabalho (Ibid.) embasou-se na tese de Wheeler (1984), que reflete sobre as influências de técnicas e do pensamento oriental na obra de artistas da dança moderna e pós-moderna norte-americana, examinando a biografia de alguns deles, como Martha Graham, Merce Cunningham, entre 
outros. Destacam-se esses dois coreógrafos em particular porque são artistas que, no entendimento de Wheeler, foram influenciados não apenas de forma superficial, mas também essencialmente pela arte oriental e por sua noção não aristotélica de tempo.

Na série de desenhos, influenciada por animes ${ }^{1}$, não existe o conceito de dobrador de tempo, mas sim de elementos naturais - água, ar, terra e fogo -, além de outros que vão se revelando ao longo dos episódios. Sobre o espectador repousa a expectativa a respeito de quais novas habilidades ainda podem vir a ser reveladas com o passar dos episódios.

Para o desenvolvimento deste texto faz-se necessária uma observação sobre a tradução do termo bender para o português. Nas dublagens da série a tradução não se faz constante: às vezes o termo é traduzido como "dominador" (sendo este predominante), às vezes como "curvador", outras vezes como “dobrador". Neste artigo, optou-se pela tradução "dobrador" devido à potencial interpretação do termo como sinônimo de expansão, e não apenas controle. Ator, dançarino e performer dobram o tempo à medida que, tecnicamente, conseguem fazer com que segundos pareçam durar mais no ato de preencher criativamente gestos feitos para a cena.

Bonfitto e Andraus (2014) analisam o conceito de kata tanto no kabuki quanto no contexto de artes marciais asiáticas, como karate-do e wushu, procurando entender se a codificação gestual limita ou potencializa a criatividade do intérprete. Concluem que é potencializadora:

[Nas] formas (kuen) de gongfu [...] a percepção revelada é a de que, por mais codificados que os movimentos sejam, quem dá sabor à forma é o artista marcial. A mesma forma executada por artistas marciais diferentes, ambos experientes, ganha tessituras singulares devido à maneira como cada um preenche os vazios entregestos. (lbid., p. 78)

A arte de ator poderia, então, ser entendida como arte de preencher vazios nos entregestos, e poder-se-ia especular que tal preenchimento estaria

1 Animes são animações que podem tomar a forma de quadrinhos, desenhos animados ou séries de televisão. No Japão o termo é utilizado para todo tipo de animação, de todos os gêneros, mas fora daquele país passou a ser usado como sinônimo de um gênero de animação japonesa que, frequentemente, tem uma versão em mangás (quadrinhos). 
ligado, metaforicamente, à arte de "dobrar o tempo". Dobrá-lo, expandi-lo, dominá-lo e curvá-lo - essas e todas as outras possíveis traduções.

A série Avatar: a lenda de Aang, criada e produzida por DiMartino e Konietzko (2003-2008), desenvolve-se em um universo fictício e mistura elementos de mitologias asiáticas, com forte influência de artes marciais e enredo voltado para todos os públicos, com especial apelo aos adolescentes. O personagem Aang seria o sucessor espiritual de uma longa linhagem de avatares, porém, sendo ele próprio um adolescente, ainda não se acha preparado para a missão de salvar o mundo da tribo do fogo, que pretende dominá-lo. Encontra-se em sua jornada com amigos que dominam os demais elementos e, com eles, aprenderá a controlá-los. Existe uma associação entre cada elemento e uma arte marcial: a água estaria ligada ao taijiquan estilo yang, a terra estaria ligada ao estilo hung ga, o fogo estaria ligado ao shaolin do Norte e o ar estaria ligado ao baguazhang. Taijiquan e baguazhang são estilos considerados internos (ANDRAUS, 2010), com movimentos leves, circulares e fluidos, enquanto os outros dois são considerados estilos externos e têm técnicas de caráter rígido.

No universo das artes marciais a subdivisão entre estilos internos e externos é didática, pois se entende que tanto os estilos ditos internos materializam o qi em movimentação visível como também os estilos considerados externos contemplam em seus gestos a noção do movimento partindo do centro de gravidade, ou dantien (HUANG, 1979). Sendo a série, no entanto, voltada para público jovem, a categorização superficial entre interno e externo e a associação com os quatro elementos - água, fogo, terra e ar - acomoda-se adequadamente com o escopo da mensagem que se pretende passar: de que a união de diferentes características potencializa a resolução de conflitos. E, tal como no mito do herói (CAMPBELL, 1990), o personagem Aang sintetizaria em si a constelação dos diferentes arquétipos, integrando-os em uma personalidade única com o poder de salvar o mundo - desde que trilhe sua própria jornada.

Aang tem 12 anos de idade, além de outros 100 anos que teria passado congelado em um iceberg, e é o último descendente da linhagem dos dobradores de ar. Para cumprir seu destino, precisa derrotar o líder da tribo do fogo, Ozai. Ele apaixona-se por Katara, que é a última dobradora da tribo da água 
do Sul. Katara também percorre, à sua maneira, uma jornada de heroína, visto que no início da saga ainda não tem o status de mestre dobradora de água, que ela virá a adquirir por meio de treinamento. Em um determinado momento da série, Katara aprende a dominar a água presente em outros elementos, como a vegetação, o sangue e o próprio ar, devido às partículas de água neles existentes.

A personagem do núcleo central que dobra terra e ensina essa arte para Aang chama-se Toph e é cega. Na história, ela aprendeu a dobrar terra com toupeiras, visto que, devido à cegueira, seus pais a consideram frágil e repudiaram, a priori, seu treinamento. Em um determinado episódio ela diz que, por ser dobradora de terra, não tem problemas para ver - em suas palavras, seus "pés podem enxergar" através das vibrações dos acontecimentos do mundo, transmitidas pelo solo, que lhe chegam aos pés. Há ainda três personagens da nação do fogo - príncipe Zuko, princesa Azula e general Iroh - com os quais Aang interage mais proximamente. A partir do contato com os outros personagens, Aang vai aprendendo as artes de que necessita para, com seu poder e consciência coletiva, neutralizar as forças de cada dobrador.

A ideia da possibilidade de dobra do tempo para este texto decorre de reflexão sobre o tempo como variável importante nas interações do homem com o mundo material. Para fundir um metal, por exemplo, reconhece-se facilmente a necessidade da ação do fogo, mas esta não se dá, quase nunca, de forma instantânea. Quanto maior a intensidade do fogo, mais instantânea será sua ação de fundir o metal, mas via de regra tem-se a imagem de uma fundição que é lenta e requer a ação do tempo - com o fogo incidindo lentamente sobre o metal e tornando-o liga metálica, dizendo-lhe algo como "seja água". A conversão das matérias umas nas outras, por analogia, remete ao processo investigativo do ator, do bailarino e do performer, dominador da arte de metamorfosear-se, de superar as próprias mesmices (CIAMPA, 1986), de verter-se em outro. Tudo isso intermediado pela dobra do tempo.

Se o ator, o dançarino e o performer podem ser entendidos como dobradores de tempo na composição do gesto, o coreógrafo e o diretor teatral, por sua vez, exercem domínio sobre o tempo na medida em que escolhem deliberadamente a duração e a ordenação das cenas. Discorre-se, nos próximos tópicos, sobre a estrutura de espetáculos na obra de dois coreógrafos 
norte-americanos - Graham e Cunningham -, e descreve-se a construção do roteiro de um espetáculo em particular, Se você se perdesse de si, inspirado na temática da doença de Alzheimer.

\section{A estrutura aristotélica e o tempo da cena em Graham e em Cunningham}

Destacam-se esses dois coreógrafos para discutir a questão do tempo na cena porque são artistas que, pode-se dizer, foram influenciados não apenas de forma superficial, mas também essencial, pela arte oriental e por sua noção não aristotélica de tempo (WHEELER, 1984, p. 111):

Martha Graham's interest in the style and philosophy of the East was influential in the development of the Graham technique and of the choreographer's theatre aesthetic. Growing up in Santa Barbara she had 'lived with an element of the Orient in the shape of Japanese and Chinese servants, gardeners, launderers, cooks which left its mark permanently upon her' (LEATHERMAN, 1966, p. 34). It was an interest in the Orient which had drawn Graham to St. Denis in the first place [...] so it was not surprising that an interest in Eastern style and philosophy remained with her even after leaving the Oriental trappings of Denishawn.

Wheeler explica que Graham teve influência dos teatros japoneses Kabuki e Nô, especialmente na forma de lidar com o tempo na construção do texto dramatúrgico, que foi herdada, posteriormente, por Merce Cunningham, e veio a influenciar os "aspectos não dança da dança pós-moderna" (Ibid., p. 105).

Ainda segundo o autor, a influência oriental propiciou que Graham rompesse com a tradição aristotélica início-clímax-fim:

Aristotle makes the classic statement of the linear conception of stage time in his definition of tragedy as 'an imitation of an action' [...]. After over two hundred years of European dramatic and choreographic activity influenced by the Poetics, Jean-Georges Noverre wrote in his monumental Letters on Dancing and Ballets (1760): 'Ballet must have a beginning, climax and end.' At the beginning of the twentieth century one could look back and see Aristotle's dictum via Noverre having determined the narrative structure of both the Romantic and Imperial Ballets. The treatment of time in the dance theatre of Graham suggests her perception of an Oriental worldview to be deep-seated indeed. While the majority of works within the Graham repertoire are 
dramatic and narrative, and in fact exhibiting development to a climax, the psychological drama of Graham offers moments which seem to extend in time. (Ibid., p. 179)

Graham recorria a uma visão cíclica de tempo, fazendo com que certos momentos se prolongassem ao invés de resultarem em uma resolução rápida da tensão do clímax. Cunningham, igualmente, rompeu com a estrutura dramatúrgica aristotélica e escolheu trabalhar o agora, o tempo presente, com clara influência da visão de mundo oriental, mediante o contato com as formas teatrais Nô e Kabuki, vivenciado inicialmente por Graham. Ambos subverteram o senso de cronologia e trabalharam com tempos cíclicos ou com a atemporalidade, recorrendo a citações dentro da própria obra e, de certa forma, trazendo para a cena a estrutura do tempo que é própria da vida. Se mundanamente tendemos a perceber o mundo pelos olhos de Chronos, há correntes de pensamento que postulam que a existência se resume a um único instante. "Life is just a breath", postula a premissa zen (CHUNG, 1997). São formas distintas de compreensão do mundo que podem não requerer a explicação de um pesquisador das artes da cena, mas que se objetificam na práxis daquele que se dedica a esculpir o tempo na arte de compor danças, peças teatrais ou performances.

\section{A concepção de Se você se perdesse de si do ponto de vista da construção do tempo}

O espetáculo Se você se perdesse de si, dirigido pela autora ${ }^{2}$, foi concebido e criado tendo como ponto de partida a doença de Alzheimer, tanto do ponto de visa da pessoa que desenvolve a doença quanto daqueles que com essa pessoa convivem. O processo teve início quando a diretora do espetáculo e duas dançarinas assistiram ao filme Still Alice, dirigido por Glatzer e Westmorland (2014) e estreado no Brasil em 2015. O filme narra a história de Alice Howland, uma professora de neurolinguística que desenvolve um quadro precoce de Alzheimer. Ela começa por esquecer palavras e, muito rapidamente, a doença progride, até a perda avançada de movimentos. Nesse

2 Uma versão compacta do espetáculo está disponível em: https://youtu.be/oP2XL2Xqzc0 Ao final da descrição do vídeo consta o link para a íntegra do espetáculo. 
processo degenerativo revelam-se as interações de Alice com seus três filhos, todos adultos. $O$ roteiro do filme terminou por influenciar expressivamente 0 roteiro do espetáculo, não de modo intencional, mas, conforme o processo de criação das cenas avançava, as relações de uma mãe com seus dois filhos se mostraram importantes para a narrativa.

Nas conversas iniciais sobre o espetáculo algumas decisões foram tomadas, como fazer o convite a dois músicos para comporem a trilha sonora e criar uma videodança que simbolizasse a infância da personagem, a ser incluída em forma de projeção como última cena do roteiro dramatúrgico embora não se tivesse, ainda, ideia de onde esse vídeo seria produzido e de qual seria exatamente o seu teor. Para a concepção e criação da videodança foi convidado, também, um especialista. Uma terceira ideia planejada desde o início seria criar cenograficamente a planta de uma casa, tendo como inspiração e referência o filme Dogville, de Lars von Trier (2003), especialmente quanto à imagem das demarcações no chão limitando as casas e seus cômodos, como se fossem paredes.

Ainda nas fases iniciais do processo adotou-se a rotina de criar as demarcações dos cômodos da casa no chão com fita crepe, de modo que o espetáculo foi criado desde o início com as ações e deslocamentos se desenvolvendo no espaço cênico que já teria o tamanho definitivo da cenografia do espetáculo. Uma vez que os deslocamentos foram espacialmente delimitados desde o início do processo criativo, também as relações temporais entre os deslocamentos foram previamente demarcadas. A participação de um dos músicos em todo o processo foi determinante para que a trilha musical tenha sido especialmente criada para esse espetáculo, com cada um de seus criadores em estreita relação conceitual com o todo da montagem.

Seguiram-se laboratórios de criação com jogos improvisacionais envolvendo as relações com a música. Aproximadamente no quarto mês do processo criativo - que se estendeu por aproximadamente nove meses - decidiu-se que o autor da trilha sonora e musical do espetáculo tomaria parte da cena como intérprete. No primeiro momento, no qual a mãe e seus dois filhos reúnem-se na sala de jantar para um jogo xadrez, o músico toca violão, em cena, conjugando as ações de tocar e de jogar e, com os sons das peças incidindo sobre o tabuleiro, compõe junto às bailarinas a base rítmica da música 
tocada pelo violão. Nessa cena a mãe começa a dar os primeiros sinais de perda da memória, ao estranhar uma das peças de xadrez (a torre, símbolo de solidez) e utilizá-la como um cálice, tentando dela beber o café - que houvera sido coado pela filha em uma pré-cena, ocorrida enquanto o público adentrava o espaço.

O processo de criação da personagem da segunda dançarina, a filha, é o ponto-chave para discutir a questão da temporalidade nesse espetáculo. Ao mesmo tempo em que ela é filha e cuidadora, é também a versão jovem da personagem principal, trazendo ao espetáculo inversões de cronologia alinhadas com a proposta de retratar a perda da memória que, além de gradativa, é não linear.

O convívio de dois intérpretes com familiares que estavam com a doença na ocasião da criação do espetáculo trouxe para o elenco a noção de não linearidade da perda progressiva da memória nas pessoas com Alzheimer. Segundo seus relatos, por vezes a pessoa se esquece de algo em um dia e consegue recuperar essa memória no dia seguinte. $O$ avanço da doença se dá ao longo de meses, ou anos, sem que necessariamente a cada dia se tenha menos memória do que no dia anterior - embora ao longo de um período essa perda seja cumulativa. Essa brecha permite discutir o tempo como constructo da percepção humana: há correntes do pensamento filosófico que entendem a noção de continuidade temporal como uma alinhavo feito pelo cérebro humano que outras espécies não necessariamente fazem. Para evitar o aprofundamento filosófico que este texto não pretende ter, atenhamo-nos ao familiar exemplo do cachorro que, ao reencontrar seu dono, expressa felicidade como se não o tivesse visto 20 ou 30 minutos antes. Considerando-se o tempo como dimensão criada e formalizada em cronologia linear pela mente humana, pode-se pensar, sobre o processo de perda de memória, que ele não necessariamente acarreta sofrimento para a pessoa doente, pois a forma como ela significa suas experiências não é mais a mesma. A noção de que o sofrimento do cuidador talvez seja maior que o do próprio doente foi trazida para o espetáculo em várias de suas cenas, costurando praticamente toda a dramaturgia elaborada.

A última cena consiste em uma videodança projetada sobre a cena ao vivo, simbolizando lembranças da infância da personagem principal em um 
circo, simultaneamente à precariedade imposta pela doença no tempo atual. $\mathrm{Na}$ videodança, a personagem principal usa roupa branca e está em um trapézio, e a segunda dançarina - ao mesmo tempo filha e versão jovem da protagonista - usa roupa preta e está em um tecido acrobático. Há um momento do vídeo em que a personagem principal, no trapézio, estende a mão tentando alcançar sua versão jovem no tecido, e nesse momento a versão jovem reage abandonando a protagonista - no espetáculo, a cena que antecede 0 vídeo indica a possibilidade dessa desistência, por parte da filha.

A trilha sonora melancoliza-se nesse momento, e parte-se para a última cena da videodança - que é também a última cena do espetáculo -, na qual a personagem principal pula em uma cama elástica como criança até que, simbolicamente, faleça - não como idosa, mas como criança. Simultaneamente, na cena sobre a qual esse vídeo se projeta, a personagem está idosa e imobilizada, porém viva. Trabalhou-se, portanto, com a ruptura da linearidade nascimento-vida-envelhecimento-morte, unindo a infância com a morte no vídeo projetado, e a velhice com a continuidade da vida na cena ao vivo - continuidade esta que levanta questionamentos sobre até que ponto vale a pena prolongar uma vida moribunda, deixando a questão em aberto para o público, sem propor nem uma nem outra possibilidade de reposta.

\section{Considerações finais}

Esta breve descrição do roteiro geral do espetáculo tem por intuito exemplificar, a partir de uma prática de criação, possibilidades de discutir a noção de tempo e seu potencial de expansão, ou de "dobra", que se dá tanto por meio da ação do intérprete que constrói o tempo cênico - prolongando o timing de um gesto, fazendo-o durar nem demais, nem de menos - quanto pela ação do coreógrafo e/ou diretor, que exerce o controle do tempo mediante as decisões referentes ao roteiro/dramaturgia.

A noção de tempo cênico, associada neste texto à ideia do ator como um dobrador de tempo, coloca-se em diálogo com a ideia de subjetivação na medida em que outorga ao ator a possibilidade subjetiva de decidir o quanto dura sua ação, mesmo quando o tempo desta está previsto em um roteiro. Ou seja, mesmo em uma coreografia predeterminada e balizada esquematicamente 
no tempo (com o recurso das contagens da música, por exemplo) é possível ao dançarino expandir cada ínfimo gesto para que ele dure uma fração de segundo a mais, e é justamente na dosagem dessa espera deliberadamente proposta pelo ator que está o ato criativo quando se trata de técnicas/danças codificadas - tal como no paradoxo de Zeno, segundo o qual, para mover-se de um ponto $A$ para um ponto $B$, é necessário mover-se até metade do caminho ${ }^{3}$. Poder-se-ia dizer que o artista acessa e traz para sua cena alguns desses entrepontos do espaço-tempo que estão, inicialmente, invisíveis ao público. Como consequência disso, ao se tomar como exemplo de técnica codificada uma performance de dança indiana ${ }^{4}$, mesmo sendo os movimentos concretamente circunscritos à tala ${ }^{5}$, cada dançarina desempenha uma performance singular.

O que propicia que determinados dançarinos, atores e/ou performers saiam sempre bem posicionados nas fotografias em movimento, enquanto outros já se encontram em transição? Além da indiscutível habilidade técnica do fotógrafo, duas possíveis respostas seriam: um bom uso do funcionamento muscular-esquelético, que lhes possibilite prolongar a duração dos movimentos, e o domínio pleno da respiração. Esses dois requisitos, em conjunto, permitem ao ator, ao dançarino e ao performer dobrar o tempo em sua busca por ressignificá-lo - ou quiçá, em alguns casos, por simplesmente dessignificá-lo.

\section{Referências bibliográficas}

ALBERGARIA, A. Mudras: o gesto da dança clássica indiana Odissi como caligrafia corporal na cena contemporânea. Dissertação de Mestrado em Artes da Cena. Universidade Estadual de Campinas, Instituto de Artes. Agência de fomento: CAPES. Campinas, SP: [s.n], 2017. Disponível em: http://www.repositorio.unicamp.br/ handle/REPOSIP/330637

3 Esse é o ponto de partida da dicotomia de Zeno, que afirma que entre dois pontos sempre será necessário percorrer metade da distância, e assim sucessivamente em regressão infinita. É, portanto, um paradoxo porque o movimento nunca de fato se iniciará (HUGGETT, 2016).

4 Toma-se a dança indiana como exemplo por ser, dentre as técnicas pesquisadas pela autora, uma das mais codificadas, incluindo-se movimentos padronizados das mãos, olhos e sobrancelhas, além do tronco e membros superiores e inferiores. Para maiores detalhes sobre Odissi ver Albergaria (2017) e Andraus, Soares e Santos (2013).

5 Tala (taal) é o sistema rítmico indiano, geralmente composto por palmas e/ou sílabas que a dançarina aprende a cantar, em conjunto com a execução de sua dança, e que, no momento da performance, são geralmente cantadas pelo(s) músico(s) e/ou pelo guru. 
ANDRAUS, M. B. M. Arte marcial na formação do artista da cena. Jundiaí: Paco Editorial, 2014.

ANDRAUS, M. B. M., SOARES, M. V., SANTOS, I. F. dos. Gestualidade da dança clássica indiana Odissi e dança contemporânea ocidental: interfaces. Sala Preta, v. 13, n. 1, jun. 2013, pp. 71-82. Disponível em: http://www.periodicos.usp.br/salapreta/article/viewFile/57532/60566

. Kungfu/Wushu: luta e arte. São Paulo: Annablume, 2010.

BONFITTO, M; ANDRAUS, M. B. M. A pregnância do vazio: a simbolização do gesto como espaço para a criação. In: SOARES, M. V.; ANDRAUS, M. B. M.; WILDHAGEN, J. (Orgs.). Mitos e símbolos na cena contemporânea: interlocuções oriente-ocidente. Jundiaí: Paco Editorial, 2014.

CAMPBELL, J. $O$ poder do mito. 25. ed. Tradução Carlos Felipe Moisés. São Paulo: Palas Athena, 1990.

CHUNG, T. C. Zen em quadrinhos. São Paulo: Ediouro, 1997.

CIAMPA, A. C. A estória do Severino e a história da Severina: um ensaio de psicologia social. São Paulo: Brasiliense, 1986.

DOGVILLE. Direção: Lars von Trier. Países Baixos: Zentropa Entertainments; Isabella Films B.V., 2003. $178 \mathrm{~min}$, color. Disponível em: <https://imdb.to/2rPOQCV>. Acesso em: 17 ago. 2016.

HUANG, A. C. L. Expansão e recolhimento: a essência do Tai Chi. São Paulo: Summus, 1979.

HUGGETT, N. Zeno's paradoxes. In: ZALTA, E. N. (Ed.). The Stanford Encyclopedia of Philosophy. Stanford, CA: Stanford University, 2010. (Winter 2010 Edition). Disponível em: <https://stanford.io/2Gr6KQT>. Acesso em: 20 ago. 2016.

INTERNET MOVIE DATABASE (IMDb). Avatar: a lenda de Aang (2003-2008). Disponível em: https://www.imdb.com/title/tt0417299/ Acesso em 17 ago. 2016.

INTERNET MOVIE DATABASE (IMDb). Still Alice (2014). Disponível em: https:// www.imdb.com/title/tt3316960/?ref_=fn_al_tt_1 Acesso em 17 ago. 2016.

WHEELER, M. F. Surface to essence: appropriation of the Orient by modern dance. 1984. 307 p. Tese (Doutorado em Educação Física) - College of Human Development and Performance, Ohio State University. Columbus, OH: OSU, 1984.

Recebido em 18/09/2016

Aprovado em 04/05/2018

Publicado em 29/06/2018 